\title{
PENGARUH PELATIHAN KERJA, PENGEMBANGAN KARIR DAN KEPUASAN KERJA TERHADAP KOMITMEN ORGANISASI KARYAWAN PT. SMART (SINAR MAS ARTA RAYA TERANG)
}

\author{
Ratna Gita Sari ${ }^{1}$, Martha Suhardiyah ${ }^{2}$ \\ Universitas PGRI AdiBuana Surabaya1,2 \\ ratnagita0606@gmail.com
}

\begin{abstract}
ABSTRAK
Dijelaskan penelitian untuk menganalisa pengaruh pelatihan kerja, pengembangan karir serta kepuasan kerja terhadap komitmen organisasi karyawan PT. SMART (Sinar Mas Arta Raya Terang). Teknik pengambilan Eksperimen Research . sampling sebanyak 75responden. Dijelaskan $t_{\text {hitung }}$ pengaruh pelatihan kerjaterhadap komitmen organisasi sebesar 1,525sig. sebesar ,132<,05. Pengembangan karir terhadap komitmen kerjamemiliki thitung sebesar 1,540sig. sebesar ,128<,05. Kepuasan kerjaterhadap komitmen organisasimemiliki thitung sebesar 2,140 sig. sebesar ,019<0,05. Hasil $\mathrm{f}_{\text {hitung }} 10,713 \mathrm{sig}, 000<, 05$. Disimpulkan adanya pengaruh secara parsial serta simultan

Kata kunci: Pelatihan kerja, pengembangan karir, kepuasan kerja \& komitmen organisasi.

ABSTRACT

Explained research to analyze the effect of job training, career development and job satisfaction on organizational commitment of employees of PT. SMART (Sinar Mas Arta Raya Terang).Research Experimental Collection techniques.sampling of 75 respondents. It was explained that the influence of job training on organizational commitment was 1,525 sig. amounted to, $132<.05$. Career development towards work commitments has a tcount of 1,540 sig. amounted to, $128<, 05$. Job satisfaction with organizational commitment has a tcount of 2,140 sig. amounted to, $019<0.05$. The results of fcount is $10,713 \mathrm{sig}$. 000, $<05$. It was concluded that there was a partial and simultaneous influence
\end{abstract}

Keyword:Job training, career development, job satisfaction \& organizational commitment. 


\section{PENDAHULUAN}

Latar Belakang

Peran sumber daya manusia kini sangatlah penting untuk membangun organisasi ataupun perusahaan agar memiliki pondasi manajemen sumber daya manusia yang unggul serta berkualitas, perusahaan berdiri atas dasar kemampuan sumber daya manusia yang unggul dalam merencakanan progress perusahaan, perusahaan tak terlepas dari strategi manajemen dalam membangun serta menumbuhkembangkan potensi SDM sesuai visi-misi perusahaan.

Sumber daya manusia menjadi faktor penentu organisasi atau perusahaan dalam mencapai tujuan serta target perusahaan yang telah ditetapkan melalui usaha yang berkesinambungan serta kooperatif orang didalamnya. Perusahaan perlu mengutamakan serta mengetahui bagaimana cara mengelola sumber daya manusia seoptimal mungkin, Sebab itu suatu perusahaan atau organisasi harus memperhatikan sumberdaya yang dimilikinya agar tetap bertahan di dalam organisasi untuk dapat mencapai tujuan yang telah di tetapkan sebelumnya.

Peranan sumber daya manusia dalam organisasi ataupun perusahaan sangat berperan penting. Berkembangnya suatu perusahaan sangat bergantung pada adanya sumber daya manusia yang berkualitas dan pengelolaannya tanpa mengesampingkan faktor penentu yang lainnya. Sebagai patokan kualitas sumber daya manusia yakni melalui skill yang dimiliki serta cara menumbuhkan potensi skill tersebut. Mencapai kepuasan kerja karyawan sangatlah penting mempertimbangkan serta mengutamakan lingkungan kerja serta penunjang kebahagiaan karyawan agar selalu maksimal dalam bekerja, karyawan harus dijamain keamanan serta kenyamanannya sebaik mungkin, semua hal harus dilakukan manajemen perusahaan dalam membangun reputasi perusahaan jangka panjang.

PT. SMART (Sinar Mas Arta Raya Terang) yang beralamatkan di Jl. Raya Jetis, Ds. Parengan, Kec. Jetis, Kab. Mojokerto Jawa Timur, Indonesia. Perusahaan ini bergerak di bidang Furniture. Perusahaan ini telah memberikan pelatihan serta pengembangan karir akan tetapi hal tersebut masih belum memberikan kepuasan terhadap para karyawannya, sehingga komitmen organisasi yang dimiliki belum dapat meningkat.

Dijelaskan fenomena diatas, Disimpulkan rumusan masalah sebagai berikut:

1. Adakahpengaruh pelatihan kerja terhadapkomitmen organisasikaryawan PT. SMART (SINAR MAS ARTA RAYA TERANG)?

2. Adakah pengaruh pengembangan karirterhadap komitmen organisasi karyawan PT. SMART (SINAR MAS ARTA RAYA TERANG)?

3. Adakah pengaruhkepuasan kerjaterhadap komitmenorganisasikaryawan PT. SMART (SINAR MAS ARTA RAYA TERANG)?

4. Adakah pengaruh pelatihan kerja, pengembangan karir \& kepuasan kerja terhadap komitmen organisasi karyawan PT. SMART (SINAR MAS ARTA RAYA TERANG)? 


\section{KERANGKA KONSEPTUAL}

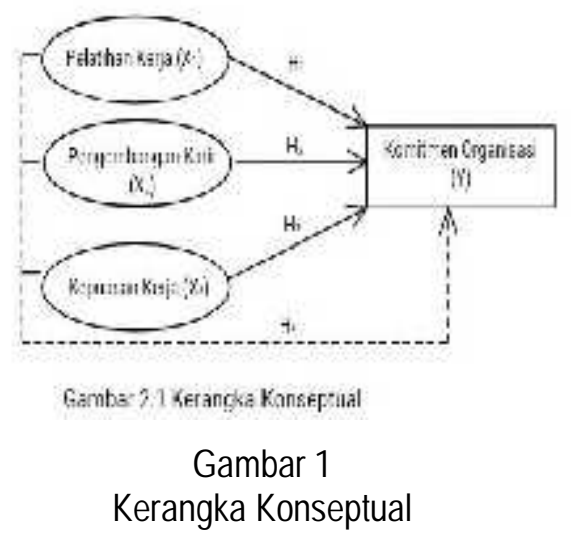

\section{METODE}

Dijelaskan pendekatan penelitianmemakaipendekatan penelitian kuantitatif serta menggunakan teknik eksperimen research, Populasi penelitian yakni karyawan produksi PT. SMART (Sinar Mas Artha Raya Terang) berjumlah 300 orang,sampel sejumlah 75 orang PT. SMART (Sinar Mas Artha Raya Terang) Mojokerto.

\section{HASIL DAN PEMBAHASAN}

Tabel 1

Hasil Uji Validitas

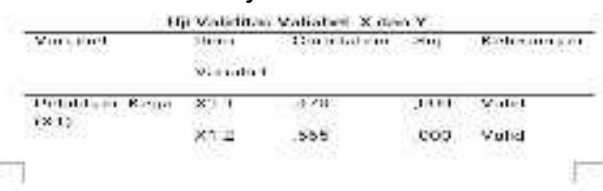

\begin{tabular}{|c|c|c|c|c|}
\hline \multicolumn{5}{|l|}{$x z$} \\
\hline & $x, x$ & shat & \multirow{2}{*}{$\mathrm{mos}$} & \multirow{2}{*}{ Walt } \\
\hline & $x_{11}$ & Sin & & \\
\hline & $x \cdots$ & seit & Ha & Wak I \\
\hline & $x \times 4$ & net & 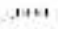 & vatus \\
\hline & $x: 7$ & $\rightarrow 0.1$ & $\cos$ & Valit \\
\hline & $x \cdot x$ & $\Leftrightarrow \infty n$ & 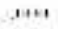 & Natu \\
\hline & $x: 4$ & $\sin$ & $x+4$ & W.1, \\
\hline & $\begin{array}{llll}x & 11\end{array}$ & ж"l & $\ldots$ & Nat-1 \\
\hline & $x \geq 11$ & $=50$ & $\cos$ & Walit \\
\hline & $\begin{array}{lll}x & 1\end{array}$ & ant. & $\cdots$ & \\
\hline \multirow{10}{*}{ (1, } & $x \times 1$ & sel & $x+1$ & $2+1=1$ \\
\hline & $x \times c$ & ans & 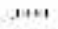 & vatus \\
\hline & $x: \times$ & $\approx n$ & tin & W.t. \\
\hline & $x \%=$ & $w x$ & 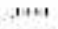 & Watu \\
\hline & $x \times=$ & $\infty$ & 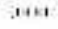 & Nat I \\
\hline & $x \times 4$ & 411 & ins & vitu \\
\hline & $x:=7$ & sinn & $\cos$ & Walit \\
\hline & $x * x$ & $\cos x$ & II. & vats \\
\hline & 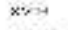 & स & $\therefore+4$ & v.tis \\
\hline & x $x$ & भश & $\cos$ & Valit \\
\hline
\end{tabular}




\begin{tabular}{|c|c|c|c|c|}
\hline & $x 2.11$ & .551 &, 000 & Valie \\
\hline & $x 2,12$ & $4 / 3$ &, 000 & Valc \\
\hline \multirow{6}{*}{$\begin{array}{l}\text { Kopuasan Kerja } \\
(x 3)\end{array}$} & $\mathrm{X} 3.1$ & 581 &, 000 & Valic. \\
\hline & $X 3.2$ & .544 & .000 & Valic \\
\hline & $\times 3.3$ & 133 &, 000 & Valc \\
\hline & $x 3.4$ & 470 & .000 & Valic \\
\hline & $X 3.5$ & 648 &, 000 & Valic \\
\hline & $X 3.5$ & 310 &, 000 & Valic \\
\hline \multirow{6}{*}{$\begin{array}{l}\text { Kom tmer } \\
\text { Orgen sasi on }\end{array}$} & $Y .1$ & .43 &, 000 & Valic \\
\hline & $\mathrm{Y} .2$ & 710 &, 000 & Valic \\
\hline & $Y 3$ & 547 & 000 & Valit. \\
\hline & $\gamma .4$ & 429 &, 000 & Valic \\
\hline & $Y .5$ & 631 & .000 & Valic \\
\hline & $\gamma \delta$ & 533 &, 000 & Vaits \\
\hline
\end{tabular}

Surnoer - Lanp ran Oulou. SPSS Pengu ien Uji Velidilas

Dijelaskan uji validitas seluruh item mempunyai nilai correlation $>0,3$, yang berarti seluruh item pernyataan telah dianggap valid.

Tabel 2

Uji Reliabilitas

\begin{tabular}{|c|c|c|c|}
\hline \multicolumn{4}{|c|}{ Uji reliabiitas Variabel $X$ dan $Y$} \\
\hline Yatiaterl & $\begin{array}{l}\text { N3iai } \\
\text { aipha }\end{array}$ & $\begin{array}{l}\text { Nilni } \\
\text { krrtiz }\end{array}$ & Ke=1teringat \\
\hline & Cromba & & \\
\hline $\begin{array}{l}\text { Pelatihan Keya } \\
\left(x_{i}\right)\end{array}$ & EUS & 06 & Relia: $=1$ \\
\hline $\begin{array}{l}\text { Pargembangm } \\
\text { Karier }(x \rightarrow)\end{array}$ & 600 & 06 & Pelisizel \\
\hline $\begin{array}{l}\text { Ke jasasan } \\
K=\text { jai } X_{j} \text { ) }\end{array}$ & 729 & 0.5 & Pelist:rl \\
\hline $\begin{array}{l}\text { Komintion } \\
\text { cige:tikakmon } \\
\text { (v) }\end{array}$ & 600 & 06 & Rellasel \\
\hline
\end{tabular}

Dijelaskansemua variabel telah memenuhi syarat, karena nilai alpha cronbach $(>0,6)$. 
Tabel 3

Uji Normalitas

\begin{tabular}{|c|c|}
\hline \multicolumn{2}{|c|}{ Uj Normalites } \\
\hline & $\begin{array}{l}\text { Ursiandardize } \\
\text { dResidual }\end{array}$ \\
\hline N & 75 \\
\hline Tes: Szatistic & 1110 \\
\hline isymo. Sig ( $(2 \cdot 13$ led $)$ & $0,57^{2}$ \\
\hline
\end{tabular}

Dijelaskan Sig. sebesar $(, 61>, 05)$. Disimpulkan pada hasil tes diatas nilai Asymp. Sig (2tailed) memenuhi syarat sehingga data dikatakan berdistribusi normal.

Tabel 4

Hasil Uji Multikolineritas

Tabel 4.12 Uj|Multikolinieritas

\begin{tabular}{|c|c|c|}
\hline \multirow{2}{*}{ Variabel } & \multicolumn{2}{|c|}{ Colinearity Statistics } \\
\hline & Tuler daice & VIF \\
\hline Pelatihan Kerja (X) & 0,678 & $1: 475 \times 10$ \\
\hline Pengembangan Karier $\left(\mathrm{X}_{2}\right)$ & 0,517 & $: 933<10$ \\
\hline Kepuasen Kcrja $\left(X_{2}\right)$ & 0,630 & $1.537 \times 10$ \\
\hline
\end{tabular}

Dijelaskan nilai tolerance lebih besar dari ,01 dan nilai VIF lebih kecil dari 10. Disimpulkan bahwa data tersebut tidak terjadi multikolonieritas.

Tabel 5

Uji Autokorelasi

Uji Autokorelasi

$\frac{\text { Durbin-Watson }}{1,754}$

Dijelaskan (Durbin Watson) sebesar 1,754,Disimpulkan model regresi berganda tidak terkena autokorelasi. 
Uji Heteroskedastisitas

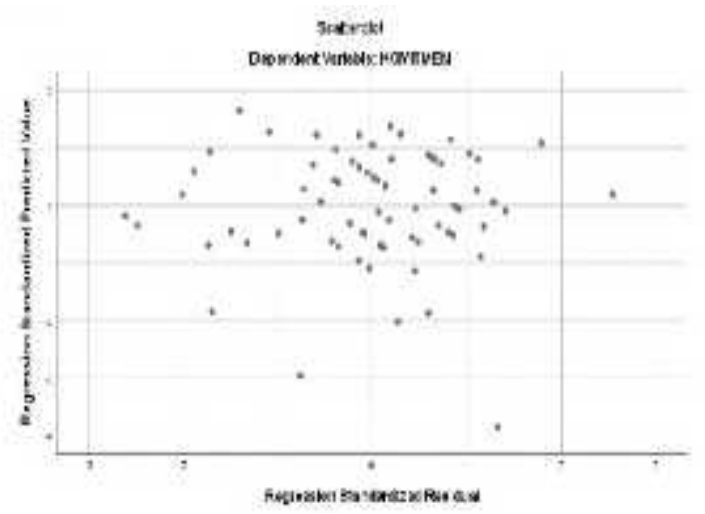

Gambar 4.1

Sumber: Hasil Pengolahan Data Primer, 2020

Gambar 2

Scatterplot

Dijelaskan gambar diatas titik-titik menyebar dengan acak pada angka 0 dan $Y$ tidak membentuk pola tertentu.

Tabel 6

\begin{tabular}{|c|c|c|}
\hline \multirow{2}{*}{ 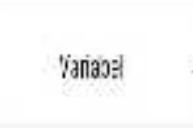 } & \multicolumn{2}{|c|}{ Unstarda daejCoefizients } \\
\hline & $E$ & S.d EIm \\
\hline IConstanti & $084 ?$ & 8,240 \\
\hline Fela:tanken: & (114] & {$[,, e t]$} \\
\hline Pengestbongzen korix & 0175 & $\cos 6$ \\
\hline Kep.zzankeria & 0311 & $0 ; 3$ \\
\hline A $\quad 2555^{\circ}$ & & \\
\hline A. Squxe: 0,312 & & \\
\hline I nilt.ng: 70,73 & & \\
\hline tial I njallit & & \\
\hline
\end{tabular}

Dijelaskan data persamaanregresisebagaiberikut :

$Y=.847+.140+.175+.314+e$

$>$ Diperoleh konstanta a sebesar .857, Data menunjukkan pelatihan kerja, pengembangan karir dan kepuasan kerja, makavariabel $x$ dan y nilai satuan .847 .

$>$ Koefesian regresi pelatihan kerja sebesar ,140. Setiap kenaikan perubahan satu pelatihan kerja akan mengakabitkan meningkatnya komitmen organisasi $(Y)$ sebesar,140. 
Koefesiansi regresi pengembangan karir sebesar,175. Kenaikan perubahan satu satuan pengembangan karir akan mengakabitka meningkatnya komitmen organisai $(Y)$ sebesar , 175.

$>$ Koefesian regresi kepuasan kerja sejumlah, 314. Adanya kenaikan satu satuan kepuasan kerja akan mengakabitkan meningkatnya komitmen organisai $(Y)$ sebesar, 314.

\begin{tabular}{|c|c|c|}
\hline \multicolumn{3}{|c|}{$\begin{array}{c}\text { Tabel } 7 \\
\text { Uji-t }\end{array}$} \\
\hline \multicolumn{3}{|c|}{ Hasil Penguj an Ujit } \\
\hline Nodel & $T$ & Sig \\
\hline Constar & 1,102 & 0,274 \\
\hline Peiatinan Kerja (xi) & 1575 & 0,132 \\
\hline Pengebangan Karir $\left(X_{2}\right)$ & 1540 & 0,128 \\
\hline Kcpuasan Ker a $\left(X_{j}\right)$ & 2140 & 0.019 \\
\hline
\end{tabular}

Dijelaskan nilai thitung pelatihan kerja sebesar 1,525, pengembangan karir sebesar 1,540, kepuasan kerja sebesar 2,140. Disimpulkan semua variabel bebas terbukti berpengaruh terhadap komitmen organisasi.

Tabel 8

Uji-f

Hasil Pengujian Uji F

\begin{tabular}{ccc}
\hline Modd & Fhitung & Sig. \\
Reglession & 0,713 & $0,000^{\mathrm{h}}$
\end{tabular}

a. Dependent Variabel Y

b. Predictors : (Constant), $X_{3} \times 2 \times 1$

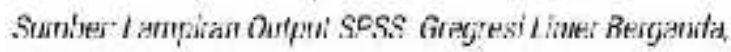
disia diotitis

Dijelaskan fhitung sebesar 10,713, Disimpulkan secara simultan adanya pengaruh.

\section{PEMBAHASAN}

Dijelaskan pelatihan kerja diperoleh thitung sebesar 1,525, demikian terbukti adanya pengaruh pelatihan kerja terhadap komitmen organisasi karyawan PT. SMART (SINAR MAS ARTA RAYA TERANG)

Dijelaskan pengembangan karir diperoleh thitung 1,540. Demikian dibuktikan adanya pengaruh pengembangan karir terhadap komitmen organisasi karyawan PT. SMART (SINAR MAS ARTA RAYA TERANG) 
Dijelaskan kepuasan kerja diperoleh thitung 2,140. Demikian adanya pengaruh kepuasan kerja terhadap komitmen organisasi karyawan PT. SMART (SINAR MAS ARTA RAYA TERANG)

Dijelaskan $f_{\text {hitung }}$ sebesar 10,713 , Disimpulkan secara simultan adanya pengaruh variabel bebas terhadap variabel terikat.

\section{SIMPULAN}

Dijelaskan hasil data diatas pelatihan kerja terbukti berpengaruh terhadap komitmen organisasi karyawan PT. SMART (SINAR MAS ARTA RAYA TERANG).

Dijelaskan pengembangan karir terbukti berpengaruh terhadap komitmen organisasi karyawan PT. SMART (SINAR MAS ARTA RAYA TERANG).

Dijelaskan data kepuasan kerja terbukti adanya pengaruh terhadap komitmen organisasi karyawan PT. SMART (SINAR MAS ARTA RAYA TERANG).

Dijelaskan fitung terbukti adanya pengaruh variabel bebas terhadap komitmen organisasi karyawan PT. SMART (SINAR MAS ARTA RAYA TERANG).

\section{IMPLIKASI}

Dari penelitian ini telah menghasilkan suatu temuan terbaru bagi perusahaan, temuan ini diharapkan bisa menjadi bahan evaluasi yang dapat digunakan oleh PT. SMART (SINAR MAS ARTA RAYA TERANG).. untuk mengambil suatu kebijakan perusahaan. Sesuai hasil temuan penulis seharusnya data ini dapat menjadi dasar bagi manajemen untuk terus berbenah memperbaiki kekurangan mana yang menjadi titik lemah perusahaan. Kini semua sektor bisnis telah memiliki kompetitor yang semakin berat sehingga dibutuhkan komitken organisasi yang kuat dari karyawan.

\section{KETERBATASAN PENELITIAN}

Dijelaskan keterbatasan penelitan penulis ketika melaksanakan penelitian dengan waktu yang sangat terbatas, responden dalam penelitian ini juga dibatasi yakni karyawan PT. SMART (SINAR MAS ARTA RAYA TERANG), penulis berharap penelitian ini dapat dijadikan pedoman bagi perusahaan PT. SMART (SINAR MAS ARTA RAYA TERANG) serta dijadikanbahan pembanding untuk penelitian terbaru lainnya.

\section{DAFTAR RUJUKAN}


Abdurahman, Maman dan Sambas Ali Muhidin, 2011, Panduan Praktis Memahami Penelitian, CV Pustaka Setia, Bandung.

Akbar, Hamid, dan Djudi, M, 2016, Pengaruh Kepuasan Kerja Terhadap Komitmen Organisasional Dan Kinerja Karyawan (Studi Pada Karyawan Tetap Pg Kebon Agung Malang). Jurnal Administrasi Bisnis S1 Universitas Brawijaya, 38(2), 79-88

Devia, A, 2016, Pengaruh Pengembangan Karir Terhadap Komitmen Organisasi (Kasus Karyawan Pt. Panin Bank Kantor Cabang Pekanbaru, JOM FISIP,3(2), 1-15.

Handoko, T Hani, 2014, Manajemen Edisi 2, BPFE Yogyakarta, Yogyakarta.

Handoko, D dan Rambe, M,F, 2018, Pengaruh Pengembangan Karir Dan Kompensasi Terhadap Komitmen Organisasi Melalui Kepuasan Kerja, Maneggio: Jurnal IImiah Magister Manajemen, 1(1), 32-45.

Indrayanto, A dan Nugroho, S, 2016, Pengaruh Pelatihan Terhadap Komitmen Organisasional dengan Organisational Based Self Esteem sebagai variabel Mediasi, 41-50. 